\title{
The Lumped Constant for the Galactose Analog 2-18 F-Fluoro-2-Deoxy-D-Galactose Is Increased in Patients with Parenchymal Liver Disease
}

\author{
Kasper S. Mikkelsen*1, Michael Sørensen*1,2 ${ }^{*}$ Kim Frisch $^{1}$, Gerda E. Villadsen ${ }^{2}$, Bo M. Bibby ${ }^{3}$, and Susanne Keiding ${ }^{1,2}$ \\ ${ }^{1}$ Department of Nuclear Medicine and PET Centre, Aarhus University Hospital, Aarhus, Denmark; ${ }^{2}$ Department of Medicine \\ (Hepatology and Gastroenterology), Aarhus University Hospital, Aarhus Denmark; and ${ }^{3}$ Department of Biostatistics, Aarhus \\ University, Aarhus, Denmark
}

\begin{abstract}
The galactose analog 2-18 F-fluoro-2-deoxy-D-galactose ( ${ }^{18} \mathrm{~F}-\mathrm{FDG}$ al) is a suitable PET tracer for measuring hepatic galactokinase capacity in vivo, which provides estimates of hepatic metabolic function. As a result of a higher affinity of galactokinase toward galactose, the lumped constant (LC) for ${ }^{18} \mathrm{~F}-\mathrm{FDG}$ al was 0.13 in healthy subjects. The aim of the present study was to test the hypothesis of a significantly different LC for ${ }^{18} \mathrm{~F}-\mathrm{FDG}$ al in patients with parenchymal liver disease. Methods: Nine patients with liver cirrhosis were studied in connection with a previous study with determination of hepatic intrinsic clearance of ${ }^{18} \mathrm{~F}-\mathrm{FDGal}\left(\mathrm{V}_{\max }^{*} / \mathrm{K}_{\mathrm{m}}^{*}\right)$. The present study determined the hepatic removal kinetics of galactose, including hepatic intrinsic clearance of galactose $\left(\mathrm{V}_{\max } / \mathrm{K}_{\mathrm{m}}\right)$ from measurements of hepatic blood flow and arterial and liver vein blood galactose concentrations at increasing galactose infusions. LC for ${ }^{18} \mathrm{~F}-\mathrm{FDGal}$ was calculated as $\left(\mathrm{V}_{\max }^{*} / \mathrm{K}_{\mathrm{m}}^{*}\right) /\left(\mathrm{V}_{\max } / \mathrm{K}_{\mathrm{m}}\right)$. On a second day, a dynamic ${ }_{18} \mathrm{~F}-\mathrm{FDGal}$ PET study with simultaneous infusion of galactose (mean arterial galactose concentration, $6.1 \mathrm{mmol} / \mathrm{L}$ of blood) and blood samples from a radial artery was performed, with determination of hepatic systemic clearance of ${ }^{18} \mathrm{~F}-\mathrm{FDGal}\left(\mathrm{K}_{+ \text {gal }}^{*}\right)$ from linear analysis of data (Gjedde-Patlak method). The maximum hepatic removal rate of galactose was estimated from ${ }^{18} \mathrm{~F}-\mathrm{FDGal}$ PET data $\left(\mathrm{V}_{\mathrm{max}}^{\mathrm{PET}}\right)$ using the estimated LC. Results: The mean hepatic $V_{\max }$ of galactose was $1.18 \mathrm{mmol} / \mathrm{min}$, the mean $\mathrm{K}_{\mathrm{m}}$ was $0.91 \mathrm{mmol} / \mathrm{L}$ of blood, and the mean $\mathrm{V}_{\max } / \mathrm{K}_{\mathrm{m}}$ was $1.18 \mathrm{~L}$ of blood $/ \mathrm{min}$. When compared with values from healthy subjects, $\mathrm{K}_{\mathrm{m}}$ did not differ $(P=0.77)$, whereas both $\mathrm{V}_{\max }$ and $\mathrm{V}_{\max } / \mathrm{K}_{\mathrm{m}}$ were significantly lower in patients (both $P<0.01$ ). Mean LC for ${ }^{18} \mathrm{~F}-\mathrm{FDG}$ al was 0.24 , which was significantly higher than the mean LC of 0.13 in healthy subjects $(P<$ 0.0001 ). Mean $\mathrm{K}_{+ \text {gal }}^{*}$ determined from the PET study was $0.019 \mathrm{~L}$ of $\mathrm{blood} / \mathrm{min} / \mathrm{L}$ of liver tissue, which was not significantly different from that in healthy subjects $(P=0.85)$. Mean hepatic $\mathrm{V}_{\max }^{\mathrm{PET}}$ was 0.57 $\mathrm{mmol} / \mathrm{min} / \mathrm{L}$ of liver tissue, which was significantly lower than the value in healthy subjects $(1.41 \mathrm{mmol} / \mathrm{min} / \mathrm{L}$ of liver tissue $(P<$ $0.0001))$. Conclusion: Disease may change the LC for a PET tracer, and this study demonstrated the importance of using the correct LC.
\end{abstract}

\footnotetext{
Received May 7, 2013; revision accepted Oct. 17, 2013.

For correspondence or reprints contact: Michael Sørensen, Department of Nuclear Medicine and PET Centre, Aarhus University Hospital, Norrebrogade 44, DK-8000 Aarhus C, Denmark.

E-mail: michael@pet.auh.dk

${ }^{*}$ Contributed equally to this work.

Published online Mar. 3, 2014.

COPYRIGHT (C 2014 by the Society of Nuclear Medicine and Molecular Imaging, Inc.
}

Key Words: hepatic removal kinetics; clearance; liver function; cirrhosis; positron emission tomography

J Nucl Med 2014; 55:590-594

DOI: 10.2967/jnumed.113.125559

\section{$\mathbf{P}$} metabolic processes. The PET tracers used may be natural substrates radiolabeled with positron-emitting isotopes such as ${ }^{11} \mathrm{C}$. However, analogs of natural substrates are commonly used, a well-known example being the glucose analog ${ }^{18}$ F-FDG used for studies of glucose metabolism. Using an analog tracer is advantageous when its metabolism is simpler, such as the metabolism of ${ }^{18}$ F-FDG, which, unlike that of glucose, essentially stops after 6-phosphorylation. Fewer kinetic parameters are thus required in the kinetic model fitted to the dynamic PET data. An important disadvantage of using an analog tracer is that it may differ from the natural substrate in its affinities for blood-to-cell transporters and intracellular enzymes responsible for the metabolism. The result of this difference is that the measured tracer kinetics may not be equal to the kinetics of the tracee. As a correction, the lumped constant (LC) has been introduced-a proportionality constant used to infer the metabolic rate of the tracee from the measured metabolic rate of the tracer. The LC is defined as follows:

$$
\mathrm{LC}=\left(\mathrm{V}_{\max }^{*} / \mathrm{K}_{\mathrm{m}}^{*}\right) /\left(\mathrm{V}_{\max } / \mathrm{K}_{\mathrm{m}}\right)
$$

Eq. 1

that is, the ratio between the intrinsic clearances of tracer (asterisk) and the tracee $(1,2)$. The partition coefficients across the plasma membrane for the 2 substrates are included in estimates of the intrinsic clearances when determined in vivo (2).

The purpose of the present study was to determine the LC for the radiolabeled galactose analog $2{ }^{18} \mathrm{~F}$-fluoro-2-deoxy-D-galactose $\left({ }^{18} \mathrm{~F}-\mathrm{FDG}\right.$ al) in patients with liver disease. Both galactose and ${ }^{18} \mathrm{~F}-\mathrm{FDG} a \mathrm{l}$ are substrates for galactokinase, a highly substrate-specific enzyme found almost exclusively in hepatocytes and responsible for 1-phosphorylation of both substrates. In healthy human subjects, the mean LC for ${ }^{18} \mathrm{~F}$-FDGal was found to be 0.13 and used to calculate the maximum hepatic removal rate of galactose $\left(\mathrm{V}_{\max }\right)$ from dynamic ${ }^{18} \mathrm{~F}$-FDGal PET data obtained during a constant infusion of galactose (3). Hepatic $\mathrm{V}_{\max }$ of galactose, which is commonly estimated by the so-called galactose 
elimination capacity test, is interesting because it yields a measure of overall metabolic liver function and provides important prognostic information for patients with acute and chronic liver disease (4-6). On the basis of unpublished experiences in cirrhotic patients, we have reasons to believe that parenchymal liver disease may significantly affect the LC for ${ }^{18} \mathrm{~F}$-FDGal, and in the present study we tested this hypothesis by determining the LC for ${ }^{18} \mathrm{~F}$ FDGal in patients with liver cirrhosis. If liver disease affects the LC, knowledge of the correct LC is important for correct calculation of the maximum hepatic removal rate of galactose from ${ }^{18} \mathrm{~F}$ FDGal PET data (i.e., $\mathrm{V}_{\max }^{\mathrm{PET}}$ ).

\section{MATERIALS AND METHODS}

Hepatic removal kinetics of galactose in vivo, including hepatic $\mathrm{V}_{\max }$ and $\mathrm{K}_{\mathrm{m}}$, were determined in 9 patients with liver cirrhosis. The investigations were performed in connection with a previously published study in which the hepatic removal kinetics of ${ }^{18} \mathrm{~F}-\mathrm{FDG}$ al, including the ratio $\mathrm{V}_{\max }^{*} / \mathrm{K}_{\mathrm{m}}^{*}$, were determined (7). This experimental setup allowed us to calculate individual values of $\mathrm{LC}$ according to Equation 1.

For in vivo estimation of the maximum hepatic removal rate of galactose in liver parenchyma from ${ }^{18} \mathrm{~F}-\mathrm{FDGal}$ PET $\left(\mathrm{V}_{\mathrm{max}}^{\mathrm{PET}}, \mathrm{mmol} / \mathrm{L}\right.$ of liver tissue/min), the patients underwent a dynamic ${ }^{18} \mathrm{~F}-\mathrm{FDG}$ al PET/ CT study within 2-3 wk with a simultaneous infusion of galactose and blood sampling from a radial artery.

No data from the present study have been published before.

The study was approved by the Central Denmark Region Committees on Biomedical Research Ethics and conducted in accordance with the 1975 Declaration of Helsinki. Informed written consent was obtained from all patients. No complications to the procedures were observed.

\section{Hepatic Removal Kinetics of Galactose and LC for ${ }^{18}$ F-FDGal}

The hepatic removal rate of galactose was measured at 6 different steady-state blood concentrations of galactose ranging from low to high, that is, from approximate first-order to near-saturated kinetics. The steady-state blood concentrations were achieved by intravenous infusions of galactose (Aarhus University Hospital Pharmacy) at 6 increasing doses $(0.70-2.90 \mathrm{mmol} / \mathrm{min})$. Each of the 6 measurement periods was preceded by a 15 - to 35 -min equilibration period after adjusting the infusion dose. The last 3 periods were furthermore initiated by a priming dose of 10-20 mmol of galactose. At each blood concentration level, 4 pairs of blood samples were collected from a radial artery and a liver vein for determination of blood galactose concentrations (8). Good approximation to constant galactose concentrations was reached in all infusion rates, with no systematic deviation, and the mean galactose concentrations in the artery $(\mathrm{A}, \mathrm{mmol} / \mathrm{L}$ of blood) and liver vein $(\mathrm{V}, \mathrm{mmol} / \mathrm{L}$ of blood) from each concentration level were used to calculate the maximum hepatic removal rate $\left(\mathrm{V}_{\max }\right.$, $\mathrm{mmol} / \mathrm{min})$ and the Michaelis constant $\left(\mathrm{K}_{\mathrm{m}}, \mathrm{mmol} / \mathrm{L}\right.$ of blood $)$ for galactose according to the sinusoidal perfusion model of in vivo enzymatic elimination $(9,10)$ by nonlinear regression of the MichaelisMenten relationship to data:

$$
\mathrm{v}=\mathrm{V}_{\max } \frac{\hat{\mathrm{C}}}{\hat{\mathrm{C}}+\mathrm{K}_{\mathrm{m}}},
$$

using the 6 sets of $\mathrm{v}$ and $\hat{\mathrm{C}}$, where $\mathrm{v}$ is the removal rate of galactose $(\mathrm{mmol} / \mathrm{min})$ calculated as $\mathrm{F}(\mathrm{A}-\mathrm{V})$ at a given $\hat{\mathrm{C}}(\mathrm{mmol} / \mathrm{L}$ of blood $)$ calculated as $(\mathrm{A}-\mathrm{V}) / \ln (\mathrm{A} / \mathrm{V}) . \mathrm{F}$ is the hepatic blood flow (L of blood/ min) determined from indocyanine green infusion and Fick's principle (3), and $\hat{\mathrm{C}}$ accounts for the decreasing blood concentration of galactose along the flow direction in the sinusoids in vivo $(9,10)$.
The intrinsic clearance of galactose was calculated as $\mathrm{V}_{\max } / \mathrm{K}_{\mathrm{m}}(\mathrm{L}$ of blood/min), and the hepatic systemic clearance of galactose $\left(\mathrm{K}_{\text {syst }}\right.$; $\mathrm{L}$ of blood/min) was calculated as follows (11):

$$
\mathrm{K}_{\mathrm{syst}}=\mathrm{F}\left(1-\mathrm{e}^{-\frac{\mathrm{V}_{\max }}{\mathrm{K} \mathrm{K}_{\mathrm{m}}}}\right)
$$

The ratios of $\mathrm{K}_{\text {syst }}$ to $\mathrm{F}$ and $\mathrm{K}_{\text {syst }}$ to $\mathrm{V}_{\text {max }} / \mathrm{K}_{\mathrm{m}}$ were used to determine whether first-order hepatic removal kinetics of galactose are predominantly flow- or enzyme-determined (11).

The LC for ${ }^{18} \mathrm{~F}-\mathrm{FDG}$ al was calculated according to Equation 1, that is, as the ratio between the hepatic intrinsic clearance of ${ }^{18} \mathrm{~F}-\mathrm{FDGal}$ (from 7) and the hepatic intrinsic clearance of galactose determined in the present study.

\section{Hepatic $\mathbf{V}_{\max }$ of Galactose Measured by ${ }^{18} \mathrm{~F}-\mathrm{FDGal}$ PET}

For the PET/CT study, a catheter was placed in a radial artery for blood sampling and in a cubital vein in both arms for infusion of galactose and injection of ${ }^{18} \mathrm{~F}-\mathrm{FDG}$. The galactose infusion (infusion rate, $2.7-5.1 \mathrm{mmol} / \mathrm{min}$ ) was started $60-70 \mathrm{~min}$ before the PET recording with a priming dose of $30-45 \mathrm{mmol}$ of galactose and continued until the end of the PET recording. The individual infusion dose was estimated from a galactose elimination capacity test $(12,13)$ performed within 2 wk of the PET study.

The subject was placed supine in a 40-slice Biograph TruePoint PET/CT camera (Siemens AG), and a topogram of the abdomen was performed for optimal positioning of the liver within the 21.6-cm transaxial field of view of the PET camera. Next, a low-dose CT scan (50 effective mAs with CAREDose $4 \mathrm{D}, 120 \mathrm{kV}$, pitch of 0.8 , and slice thickness of $5 \mathrm{~mm}$ ) was performed for definition of anatomic structures and attenuation correction of the PET data. Simultaneously with the start of a 60-min dynamic PET recording, a bolus of $100 \mathrm{MBq}$ of ${ }^{18} \mathrm{~F}-\mathrm{FDGal}$ (range, $96-104 \mathrm{MBq}$ ) in $10 \mathrm{~mL}$ of saline was administered intravenously, and the intravenous line flushed with $15 \mathrm{~mL}$ of saline. ${ }^{18} \mathrm{~F}-\mathrm{FDG}$ al was produced as previously described, with a radiochemical purity of $98 \% \pm 1 \%$ (14).

During the PET recording, blood samples $(0.5 \mathrm{~mL})$ were collected from the radial artery at $18 \times 5,6 \times 10,3 \times 20,3 \times 60,1 \times 120,1 \times 240$, $1 \times 360$, and $4 \times 600 \mathrm{~s}$ for determination of ${ }^{18} \mathrm{~F}-\mathrm{FDG}$ al blood concentrations. Radioactivity concentrations were measured in a well counter (Packard Instruments) and corrected for radioactive decay back to the start of the PET recording, yielding a blood time-activity curve (timeactivity curve blood $; \mathrm{kBq} / \mathrm{L}$ of blood vs. time in minutes). At time 0,20 , 40 , and $60 \mathrm{~min}$, arterial blood samples $(0.5 \mathrm{~mL})$ were collected for determination of blood concentration of galactose (8). In each individual, good approximation to a constant galactose concentration was achieved during the PET study, and the individual mean arterial galactose concentration $\left(\mathrm{C}_{\mathrm{a}}, \mathrm{mmol} / \mathrm{L}\right.$ of blood) was used for the calculation of $\mathrm{V}_{\max }^{\mathrm{PET}}$.

PET data were reconstructed using iterative processing and a timeframe structure of $18 \times 5,15 \times 10,4 \times 30,4 \times 60$, and $10 \times 300 \mathrm{~s}$ (total, $60 \mathrm{~min}$ ) and corrected for radioactive decay back to the start of the recording, yielding images of $128 \times 128 \times 47$ voxels and a central spatial resolution of $6.7 \mathrm{~mm}$ (full width at half maximum); voxel size was $2.4 \times 2.4 \times 3.1 \mathrm{~mm}$. Using the combined PET/CT images, a volume of interest was drawn in the liver tissue $1.5-2 \mathrm{~cm}$ from the edge of the liver and avoiding the central parts of the liver. For each volume of interest, the time-activity curve (time-activity curve ${ }_{\text {liver }}, \mathrm{kBq} / \mathrm{L}$ of liver tissue vs. time in minutes) was generated.

The hepatic systemic clearance of ${ }^{18} \mathrm{~F}-\mathrm{FDG}$ al per volume of liver tissue $\left(\mathrm{K}_{+ \text {gal }}^{*} ; \mathrm{L}\right.$ blood/min/L of liver tissue) was calculated as the asymptote fitted to Gjedde-Patlak $(15,16)$ representation of time-activity curve blood $_{\text {and time-activity curve }}$ liver using data from 6 to $20 \mathrm{~min}$ after the ${ }^{18} \mathrm{~F}$-FDGal administration (quasi-steady-state metabolism) $(3,7,17)$. 
The hepatic $\mathrm{V}_{\max }$ for galactose per volume of liver tissue $\left(\mathrm{V}_{\max }^{\mathrm{PET}}\right.$; $\mathrm{mmol} / \mathrm{min} / \mathrm{L}$ of liver tissue) was calculated as follows $(3,17)$ :

$$
\mathrm{V}_{\max }^{\mathrm{PET}}=\frac{\mathrm{K}_{+\mathrm{gal}}^{*} \mathrm{C}_{\mathrm{a}}}{\mathrm{LC}}\left(\frac{\mathrm{K}_{\mathrm{m}}+\hat{\mathrm{C}}}{\hat{\mathrm{C}}}\right) .
$$

The term $\left(\mathrm{K}_{\mathrm{m}}+\hat{\mathrm{C}}\right) / \hat{\mathrm{C}}$ corrects for the individual degree of saturation of the hepatic galactose elimination. At near-saturated kinetics, the difference between $C_{a}$ and $\hat{C}$ becomes negligible, and $C_{a}$ was accordingly used since $\mathrm{V}$ was not measured in this part of the experiment.

\section{Statistics}

The estimation of $\mathrm{V}_{\max }$ and $\mathrm{K}_{\mathrm{m}}$ values included SEs of the estimates of $\mathrm{v}$ and $\hat{\mathrm{C}}$ in the nonlinear regression of the implicit relationship between the variables given by Equation 2, using maximum likelihood estimation $(10,18)$. Linear regression was used for the calculation of the hepatic systemic clearance of ${ }^{18} \mathrm{~F}-\mathrm{FDGal}$ from PET data according to the Gjedde-Patlak method with maximum-likelihood estimation. The Student $t$ test was used for comparison of mean values between cirrhotic patients and healthy subjects. A $P$ value of less than 0.05 was considered to indicate a statistically significant difference.

\section{RESULTS}

\section{Hepatic Removal Kinetics of Galactose and LC for ${ }^{18}$ F-FDGal}

The mean hepatic $\mathrm{V}_{\max }$ of galactose was $1.18 \mathrm{mmol} / \mathrm{min}$, and mean $\mathrm{K}_{\mathrm{m}}$ was $0.91 \mathrm{mmol} / \mathrm{L}$ of blood (Table 1 ). When compared with values from healthy subjects (3), $\mathrm{V}_{\max }$ was significantly lower $(P<0.01)$ whereas $\mathrm{K}_{\mathrm{m}}$ was not statistically significantly different $(P=0.77)$. Mean $\mathrm{V}_{\text {max }} / \mathrm{K}_{\mathrm{m}}$ was $1.18 \mathrm{~L}$ of blood $/$ min (Table 1$)$, which was significantly lower than that in healthy subjects $(P<$ 0.001) (3). The estimates of $\mathrm{V}_{\max }$ and $\mathrm{K}_{\mathrm{m}}$ were highly correlated within each individual (mean correlation, 94\%; range, 89\%-97\%), and the individual $\mathrm{V}_{\max } / \mathrm{K}_{\mathrm{m}}$ ratios were accordingly estimated with high accuracy.

Mean $\mathrm{K}_{\text {syst }}$ was $0.80 \mathrm{~L}$ of blood/min, with a mean approximation to the hepatic blood flow of $73 \%$, which was significantly lower $(P=0.001)$ than the approximation of $\mathrm{K}_{\text {syst }}$ to the hepatic blood flow of $92 \%$ in healthy subjects (3). The mean approximation of $\mathrm{K}_{\text {syst }}$ to $\mathrm{V}_{\text {max }} / \mathrm{K}_{\mathrm{m}}$ was $55 \%$, which was significantly higher $(P=0.0001)$ than the approximation of $36 \%$ in healthy humans (3). Accordingly, although hepatic systemic clearance of galactose is predominantly flow-determined in patients with cirrhosis, the contribution from enzymatic capacity on the estimate is not negligible.

The LC for ${ }^{18} \mathrm{~F}$-FDGal ranged from 0.18 to 0.29 , with a weighted mean of 0.24 (Table 1), which was significantly higher $(P<0.0001)$ than the mean LC of 0.13 in healthy subjects $(3)$.

There were no significant correlations between $\mathrm{LC}$ and $\mathrm{V}_{\max }$, galactose elimination capacity, or $\mathrm{K}_{- \text {gal }}^{*}($ all, $P>0.05)$.

\section{Hepatic $\mathbf{V}_{\max }$ of Galactose Measured by ${ }^{18} \mathrm{~F}-\mathrm{FDG}$ al PET}

Mean $\mathrm{C}_{\mathrm{a}}$ during the PET recording was $6.1 \mathrm{mmol} / \mathrm{L}$ of blood (range, 4.7-7.5 mmol/L of blood). This yielded a mean approximation to saturated kinetics of $86 \%$ (range, $72 \%-92 \%$ ). Mean $\mathrm{K}_{+ \text {gal }}^{*}$ was $0.019 \mathrm{~L}$ of blood $/ \mathrm{min} / \mathrm{L}$ of liver tissue (Table 2 ), which was not significantly different from that in healthy subjects $(P=$ $0.85)$ (3). Mean hepatic $\mathrm{V}_{\max }^{\mathrm{PET}}$ was $0.57 \mathrm{mmol} / \mathrm{min} / \mathrm{L}$ of liver tissue (Table 2$)$, which was significantly lower $(P<0.0001)$ than the value of $1.41 \mathrm{mmol} / \mathrm{min} / \mathrm{L}$ of liver tissue in healthy subjects (3).

\section{DISCUSSION}

When quantitative PET studies of metabolic processes using a tracer analog are performed, it is important to know how disease

TABLE 1

Patient Characteristics and Hepatic Removal Kinetics of Galactose and LC for ${ }^{18} \mathrm{~F}-\mathrm{FDGal}$ in Patients with Liver Disease

\begin{tabular}{|c|c|c|c|c|c|c|c|c|}
\hline Patient no. & Sex & Age (y) & $\begin{array}{c}\text { Body } \\
\text { weight }(\mathrm{kg})\end{array}$ & Etiology & $\begin{array}{c}\mathrm{V}_{\max } \\
(\mathrm{mmol} / \mathrm{min})\end{array}$ & $\begin{array}{c}\mathrm{K}_{\mathrm{m}}(\mathrm{mmol} / \mathrm{L} \\
\text { of blood) }\end{array}$ & $\begin{array}{c}\mathrm{V}_{\max } / \mathrm{K}_{\mathrm{m}}(\mathrm{L} \text { of } \\
\mathrm{blood} / \mathrm{min})\end{array}$ & LC \\
\hline 1 & Male & 61 & 70 & Alcohol & $1.52 \pm 0.40$ & $0.81 \pm 0.40$ & $1.88 \pm 0.33$ & $0.18 \pm 0.05$ \\
\hline 2 & Male & 66 & 86 & Alcohol & $1.56 \pm 0.17$ & $0.93 \pm 0.19$ & $1.68 \pm 0.14$ & $0.23 \pm 0.03$ \\
\hline 3 & Female & 60 & 82 & Cryptogenic & $1.01 \pm 0.10$ & $1.00 \pm 0.22$ & $1.00 \pm 0.13$ & $0.23 \pm 0.04$ \\
\hline 4 & Male & 57 & 79 & Alcohol + HCV & $1.48 \pm 0.52$ & $1.41 \pm 0.77$ & $1.05 \pm 0.25$ & $0.27 \pm 0.08$ \\
\hline 5 & Female & 71 & 83 & Cryptogenic & $2.16 \pm 0.27$ & $1.96 \pm 0.43$ & $1.10 \pm 0.12$ & $0.29 \pm 0.05$ \\
\hline 6 & Male & 51 & 93 & Alcohol & $1.17 \pm 0.22$ & $0.48 \pm 0.20$ & $2.42 \pm 0.39$ & $0.18 \pm 0.04$ \\
\hline 7 & Male & 62 & 90 & Alcohol & $1.19 \pm 0.18$ & $0.82 \pm 0.26$ & $1.45 \pm 0.24$ & $0.22 \pm 0.08$ \\
\hline 8 & Male & 65 & 62 & Alcohol & $0.95 \pm 0.11$ & $1.19 \pm 0.22$ & $0.79 \pm 0.08$ & $0.28 \pm 0.03$ \\
\hline 9 & Male & 43 & 70 & Alcohol & $1.75 \pm 0.35$ & $0.80 \pm 0.23$ & $2.17 \pm 0.16$ & ND \\
\hline Mean \pm SE & & & & & $1.18 \pm 0.06^{\dagger}$ & $0.91 \pm 0.08$ & $1.18 \pm 0.05^{\ddagger}$ & $0.24 \pm 0.02^{\S}$ \\
\hline \multicolumn{9}{|c|}{ Healthy subjects } \\
\hline Mean & & & & & 2.66 & 0.95 & 2.74 & 0.13 \\
\hline Range & & & & & $1.81-5.34$ & $0.59-2.17$ & $2.16-3.13$ & $0.10-0.17$ \\
\hline \multicolumn{7}{|c|}{$\begin{array}{l}\mathrm{HCV}=\text { hepatitis } \mathrm{C} \text { virus; ND }=\text { intrinsic clearance of }{ }^{18} \mathrm{~F}-\mathrm{FDGal} \text { could not be determined }(7) \text {; mean } \pm \mathrm{SE}=\text { weighted mean } \pm \mathrm{SE} \text { of } \\
\text { weighted mean. } \\
\mathrm{V}_{\max } \text { and } \mathrm{K}_{\mathrm{m}} \text { were calculated according to Equation } 2 \text {; LC was calculated according to Equation 1. Individual data are given as mean } \pm \\
\text { SE of estimate. Data from healthy subjects are from Sørensen et al. (3). }\end{array}$} & & \\
\hline
\end{tabular}


TABLE 2

Hepatic $V_{\max }$ for Galactose Determined from ${ }^{18} \mathrm{~F}-\mathrm{FDG}$ al $\mathrm{PET} / \mathrm{CT}$

\begin{tabular}{lcc}
\hline Patient no. & $\begin{array}{c}\mathrm{K}_{+ \text {gal }}^{*} \\
\text { (L blood/min/L } \\
\text { of liver) }\end{array}$ & $\begin{array}{c}\mathrm{V}_{\max }^{\text {PET }} \\
\text { (mmol galactose/min/L } \\
\text { of liver) }\end{array}$ \\
\hline 1 & $0.014 \pm 0.002$ & $0.54 \pm 0.31$ \\
2 & $0.026 \pm 0.001$ & $0.69 \pm 0.18$ \\
3 & $0.020 \pm 0.001$ & $0.74 \pm 0.24$ \\
4 & $0.022 \pm 0.001$ & $0.70 \pm 0.45$ \\
5 & $0.039 \pm 0.003$ & $0.96 \pm 0.32$ \\
6 & $0.007 \pm 0.002$ & $0.27 \pm 0.15$ \\
7 & $0.007 \pm 0.001$ & $0.21 \pm 0.11$ \\
8 & $0.015 \pm 0.001$ & $0.47 \pm 0.11$ \\
9 & $0.023 \pm 0.002$ & $\mathrm{ND}$ \\
Mean \pm SE & $0.019 \pm 0.001$ & $0.57 \pm 0.06{ }^{\dagger}$ \\
Healthy subjects & 0.019 & 1.41 \\
Mean & $0.011-0.029$ & $1.10-2.11$ \\
Range & &
\end{tabular}

${ }^{\dagger} P<0.0001$ when compared with healthy subjects.

$\mathrm{K}_{+ \text {gal }}^{*}=$ hepatic systemic clearance of ${ }^{18} \mathrm{~F}-\mathrm{FDGal}$ determined from ${ }^{18} \mathrm{~F}-\mathrm{FDGal}$ PET/CT with infusion of galactose; $\mathrm{V}_{\max }^{\mathrm{PET}}=$ maximum hepatic removal rate of galactose determined from ${ }^{18} \mathrm{~F}$ FDGal PET/CT according to Equation 4; ND = not determined (LC not available; Table 1); mean \pm SE $=$ weighted mean \pm SE of weighted mean.

Individual data are given as mean \pm SE of estimate. Data from healthy subjects are from Sørensen et al. (3).

may affect the LC for the tracer. The present study demonstrated how cirrhosis significantly increases the LC for the galactose analog ${ }^{18} \mathrm{~F}$-FDGal in liver tissue when compared with previously published values of LC in healthy subjects determined using the same experimental setup (3).

In accordance with the fact that patients with cirrhosis have decreased metabolic liver function, $\mathrm{V}_{\max }$ was significantly lower than the mean value previously found in healthy subjects (Table 1) when measured directly from galactose infusions and blood samples from an artery and a liver vein. When hepatic galactose $V_{\max }$ was calculated from the dynamic ${ }^{18} \mathrm{~F}-\mathrm{FDGal}$ PET study with simultaneous infusion of galactose (i.e., $\mathrm{V}_{\max }^{\mathrm{PET}}$ ) and corrected for the individual LC, this value was also significantly lower in patients than in healthy subjects (Table 2). Interestingly, the mean hepatic systemic clearance of ${ }^{18} \mathrm{~F}-\mathrm{FDGal}\left(\mathrm{K}_{+\mathrm{gal}}^{*}\right)$, as derived from the PET data and arterial blood concentrations of ${ }^{18} \mathrm{~F}$-FDGal, was not significantly different from the mean value in healthy subjects (3). Accordingly, if not corrected by the correct LC (Eq. 4), the calculation of $\mathrm{V}_{\max }^{\mathrm{PET}}$ would have provided erroneously high values in the patients with cirrhosis when compared with the healthy subjects.

The LC was significantly lower than unity in both patients with cirrhosis and healthy subjects as a result of the high substrate specificity of galactokinase (3). Interestingly, the different affinities of galactokinase for ${ }^{18} \mathrm{~F}-\mathrm{FDGal}$ and galactose caused the hepatic systemic clearance of ${ }^{18} \mathrm{~F}$-FDGal to be enzyme-determined in both patients with cirrhosis and healthy subjects $(3,7)$ whereas the hepatic systemic clearance of galactose was flow-determined in both groups of subjects. When galactose is used for measurements of hepatic metabolic function, a relatively high blood concentration of galactose is accordingly required to achieve a nearsaturated hepatic removal rate of galactose to avoid the influence of possible changes in hepatic blood flow on the estimate. In contrast, the hepatic systemic clearance of ${ }^{18} \mathrm{~F}-\mathrm{FDGal}$ is enzyme-determined in both patients with cirrhosis and healthy subjects $(3,7)$. The measured hepatic systemic clearance of ${ }^{18} \mathrm{~F}-\mathrm{FDGa}$ obtained from the PET study without infusion of galactose (i.e., $\mathrm{K}^{*}{ }_{\text {gal }}$ ) accordingly approximates the hepatic intrinsic clearance of ${ }^{18} \mathrm{~F}-\mathrm{FDGal}\left(\mathrm{V}_{\max }^{*} / \mathrm{K}_{\mathrm{m}}^{*}\right)$ and not flow. The Michaelis constant for ${ }^{18} \mathrm{~F}-\mathrm{FDGal}\left(\mathrm{K}_{\mathrm{m}}^{*}\right)$ cannot be determined independently, only as the ratio $V_{\max }^{*} / K_{m}^{*}(3,7)$. Since $K_{m}$ for galactose was similar in healthy subjects and patients with cirrhosis (Table 1), it is unlikely that $\mathrm{K}_{\mathrm{m}}^{*}$ should differ between the 2 groups of subjects. $\mathrm{K}_{- \text {gal }}^{*}$ accordingly reflects $\mathrm{V}_{\text {max }}^{*}$ and thus provides a measurement of the hepatic galactokinase capacity for ${ }^{18} \mathrm{~F}$-FDGal without the need for correction by the LC. In accordance, $\mathrm{K}_{- \text {gal }}^{*}$ was significantly lower in patients with cirrhosis than in healthy subjects $(3,7)$. These kinetic features also mean that if the same patient is followed over time, any observed changes in $\mathrm{K}_{- \text {gal }}^{*}$ reflect changes in $\mathrm{V}_{\text {max }}^{*}$ and not changes in $\mathrm{K}_{\mathrm{m}}^{*}$ or hepatic blood flow.

The present results demonstrated the importance of applying the correct LC in PET studies in which a tracee is present in significant concentrations compared with the tracer. This finding does not affect the use of ${ }^{18} \mathrm{~F}$-FDGal as a PET tracer of hepatic metabolic function because the kinetic properties of the tracer are so favorable that the investigation can be performed without coadministration of galactose, that is, tracer only. This abolishes the need for correcting the ${ }^{18} \mathrm{~F}$-FDGal clearance measurements by LC since galactose is not present in blood during fasting. However, for other tracers such as the glucose analog ${ }^{18} \mathrm{~F}-\mathrm{FDG}$, it is important to know the correct LC because of the presence of glucose in blood. The mean LC for ${ }^{18} \mathrm{~F}$-FDGal was 0.14 in healthy anesthetized pigs (17), which is not significantly different from the mean LC of 0.13 in healthy human subjects (3). For other tracers, species differences must be considered a possibility, especially in disease, and determination of the LC in human subjects should therefore be preferred. Furthermore, for an organ such as the brain, which comprises functionally and structurally different structures, potential regional differences in the LC of the PET tracer must also be considered (2).

\section{CONCLUSION}

The LC for a PET tracer can be significantly affected by disease, as shown in the present study in which the LC for ${ }^{18} \mathrm{~F}$ FDGal in patients with liver cirrhosis was significantly higher than the mean LC previously determined in healthy subjects. The results underline the importance of applying the correct LC when performing PET studies; an LC for a PET tracer determined in healthy subjects cannot be uncritically applied to patients, and even for patients, a universal mean value may not be possible to obtain. However, the kinetic properties of ${ }^{18} \mathrm{~F}$-FDGal make it possible to perform PET studies of hepatic metabolic function in terms of ${ }^{18} \mathrm{~F}-\mathrm{FDGal} \mathrm{V}_{\max }$ in the liver parenchyma $\left(\sim \mathrm{V}_{\max }^{\mathrm{PET}}\right)$ without correction by LC.

\section{DISCLOSURE}

The costs of publication of this article were defrayed in part by the payment of page charges. Therefore, and solely to indicate this fact, this article is hereby marked "advertisement" in accordance with 18 USC section 1734. This study was supported in part by the Danish Council for Independent Research (Medical Sciences, 09-067618 and 09-073658), NIH (R01-DK074419), the A.P. Møller 
Foundation for the Advancement of Medical Science, the Novo Nordisk Foundation, Aase and Ejnar Danielsen's Foundation, and Christian and Ottilia Brorson's Foundation. No other potential conflict of interest relevant to this article was reported.

\section{REFERENCES}

1. Sokoloff L, Reivich M, Kennedy C, et al. The $\left[{ }^{14} \mathrm{C}\right]$ deoxyglucose method for the measurement of local cerebral glucose utilization: theory, procedure, and normal values in the conscious and anesthetized albino rat. J Neurochem. 1977;28:816-897.

2. Bass L, Sørensen M, Lajord Munk O, Keiding S. Analogue tracers and lumped constant in capillary beds. J Theor Biol. 2011;285:177-181.

3. Sørensen M, Mikkelsen KS, Frisch K, Bass L, Bibby BM, Keiding S. Hepatic galactose metabolism quantified in humans using $2-{ }^{18} \mathrm{~F}$-fluoro-2-deoxy-D-galactose PET/CT. J Nucl Med. 2011;52:1566-1572.

4. Merkel C, Marchesini G, Fabbri A, et al. The course of galactose elimination capacity in patients with alcoholic cirrhosis: possible use as a surrogate marker for death. Hepatology. 1996;24:820-823.

5. Schmidt LE, Ott P, Tygstrup N. Galactose elimination capacity as a prognostic marker in patients with severe acetaminophen-induced hepatotoxicity: 10 years' experience. Clin Gastroenterol Hepatol. 2004;2:418-424.

6. Jepsen P, Vilstrup H, Ott P, Keiding S, Andersen PK, Tygstrup N. The galactose elimination capacity and mortality in 781 Danish patients with newly-diagnosed liver cirrhosis: a cohort study. BMC Gastroenterol. 2009;9:50.

7. Sørensen M, Mikkelsen KS, Frisch K, Villadsen GE, Keiding S. Regional metabolic liver function measured by $2-\left[{ }^{18} \mathrm{~F}\right]$ fluoro-2-deoxy-D-galactose PET/CT in patients with cirrhosis. J Hepatol. 2013;58:1119-1124.
8. Kurz G, Wallenfels K. D-galactose, UV-test mit galactose-dehydrogenase. In: Bergmeyer HU, ed. Methoden der Enzymatischen Analyse. Weinheim, Germany: Verlag Chemie; 1970:1241-1244.

9. Bass L, Keiding S, Winkler K, Tygstrup N. Enzymatic elimination of substrates flowing through the intact liver. J Theor Biol. 1976;61:393-409.

10. Keiding S, Johansen S, Winkler K, Tønnesen K, Tygstrup N. Michaelis Menten kinetics of galactose elimination by the isolated perfused pig liver. Am J Physiol. 1976;230:1302-1313.

11. Winkler K, Bass L, Keiding S, Tygstrup N. The physiological basis for clearance measurements in hepatology. Scand J Gastroenterol. 1979;14:439-448.

12. Tygstrup N. Determination of the hepatic elimination capacity $(\mathrm{Lm})$ of galactose by single injection. Scand J Clin Lab Invest Suppl. 1966;18:118-125.

13. Tygstrup N. Effect of sites of blood sampling in determination of the galactose elimination capacity. Scand J Clin Lab Invest. 1977;37:333-338.

14. Frisch K, Bender D, Hansen SB, Keiding S, Sørensen M. Nucleophilic radiosynthesis of $2-\left[{ }^{18} \mathrm{~F}\right]$ fluoro-2-deoxy-D-galactose from Talose triflate and biodistribution in a porcine model. Nucl Med Biol. 2011;38:477-483.

15. Gjedde A. Calculation of cerebral glucose phosphorylation from brain uptake of glucose analogs in vivo: a re-examination. Brain Res. 1982;257:237-274.

16. Patlak CS, Blasberg RG, Fenstermacher JD. Graphical evaluation of blood-tobrain transfer constants from multiple-time uptake data. J Cereb Blood Flow Metab. 1983;3:1-7.

17. Sørensen M, Munk OL, Mortensen FV, et al. Hepatic uptake and metabolism of galactose can be quantified in vivo by $2-\left[{ }^{18} \mathrm{~F}\right]$ fluoro-2-deoxygalactose positron emission tomography. Am J Physiol Gastrointest Liver Physiol. 2008;295: G27-G36.

18. Seber GAF, Wild CJ. Non-Linear Regression. New York, NY: John Wiley and Sons; 1989. 